\title{
Análise Calorimétrica aplicada a Polímeros Biológicos
}

\author{
Parte I: Fundamentos Teóricos
}

MARIA HELENA CASIMIRO 1, JO ÃO PA U L LEAL ${ }^{2,3}$ M. HELENA GIL ${ }^{4}$, CARLOS A. NIETO DE CASTRO 3,*

Resumo Pretende-se com este trabalho ilustrar a importância do conhecimento aprofundado da estrutura e comportamento dos polímeros biológicos, evidenciando a versatilidade da análise calorimétrica na caracterização dessas macromoléculas e das suas possíveis interacções. Numa primeira parte efectua- -se uma breve visita a alguns dos fundamentos das técnicas calorimétricas com aplicabilidade nesta área, enquanto que na segunda parte se apresentam alguns exemplos da aplicabilidade e versatilidade das técnicas calorimétricas na análise de macromoléculas biológicas.

\section{Introdução}

O conhecimento aprofundado da estrutura das macromoléculas biológicas, quer sejam proteínas, ácidos nucleicos, polissacarídeos, membranas biológicas, etc., permite esclarecer as suas funções enquanto compostos intervenientes no processo metabólico dos seres vivos.

Este conhecimento reveste-se actualmente de particular relevância em virtude de poder ser utilizado na concepção de novas aplicações biomédicas (fármacos e/ou dispositivos médicos), assim como na obtenção de moléculas modificadas com propriedades melhoradas para aplicação a nível industrial.

Os polímeros biológicos apresentam-se bastante mais complexos do que as moléculas orgânicas comuns. Esta complexidade advém do elevado número de átomos presentes numa macromolécula biológica e da possibilidade de rotação relativamente livre em torno das muitas ligações covalentes da macromolécula. Assim, as reduzidas barreiras energéticas rotacionais proporcionam a este tipo de moléculas flexibilidade e elevada complexidade conformacional e, consequentemente, o número de estruturas tri-dimensionais teoricamente possíveis que uma macromolécula pode apresentar é enorme. Não obstante, cada polímero biológico adopta uma conformação tri-dimensional distinta, a que lhe é mais favorável em termos energéticos, designada por conformação nativa.

Por outro lado, a nível biológico, as possíveis interacções entre diferentes macromoléculas com elevada especificidade, por exemplo proteína-ADN, hormona-receptor, anticorpo-antigene, etc., ilustram bem a complexidade e diversidade dos mecanismos envolvidos no reconhecimento molecular. A importância de tais interacções nos processos biológicos é indiscutível, revestindo-se de grande interesse a determinação da natureza das forças intervenientes em cada uma delas.

Atendendo ao exposto, facilmente se depreende que a compreensão das macromoléculas biológicas e das suas interacções passa não só pelo conhecimento da sua estrutura, mas também pelo conhecimento das componentes energéticas associadas a estas interacções. No entanto, nem sempre os meios técnicos disponíveis proporcionaram este tipo de abordagem.

Nos últimos anos a inovação tecnológica tem possibilitado o desenvolvimento de novos métodos de análise. Destes novos métodos, destacam-se em lugar cimeiro os métodos calorimétricos, de elevada sensibilidade, capazes de fornecer informação directa acerca da energia envolvida nos processos anteriormente mencionados. A esses processos encontra-se associada a libertação e/ou absorção de energia calorífica, podendo assim ser representadas em termos de variações térmicas.

Estes métodos calorimétricos, juntamente com toda uma vasta gama de técnicas analíticas que permitem medir alterações das propriedades químicas e/ou físicas de uma amostra em função da temperatura, constituem aquilo a que se designa de um modo generalizado por Análise Térmica.

1 Departamento de Física, Instituto Tecnológico e Nuclear, 2686-953 Sacavém, Portugal

2 Departamento de Química, Instituto Tecnológico e Nuclear, 2686-953 Sacavém, Portugal

3 Departamento de Química e Bioquímica, Faculdade de Ciências, Universidade de Lisboa, 1749-016 Lisboa; e-mail:cacastro@fc.ul.pt

4 Departamento de Engenharia Química, Faculdade de Ciências e Tecnologia, Universidade de Coimbra, Pólo II Pinhal de Marrocos, 3030-290 Coimbra, Portugal 


\section{Análise Térmica}

O termo Análise Térmica ( Thermal Analysis, TA) é, tal como já foi mencionado, frequentemente utilizado para descrever técnicas analíticas que investigam o comportamento de amostras em função da temperatura. Com efeito, quando submetida a uma variação de temperatura, uma dada substância pode sofrer alterações físicas e/ou químicas, reagir com os componentes do meio ambiente, perder água de cristalização, etc., sendo que muitas dessas transformações são acompanhadas pela perda ou absorção de energia calorífica.

A Confederação Internacional de Análise Térmica e Calorimetria (ICTAC) define análise térmica como um grupo de técnicas analíticas nas quais uma propriedade da amostra é monitorada em função da temperatura ou do tempo, enquanto a amostra é sujeita a um variação programada de temperatura em atmosfera específica. Acrescenta ainda que essa variação pode envolver aquecimento ou arrefecimento, a velocidade fixa ou variável, manutenção da amostra a temperatura constante, ou qualquer sequência destas três possibilidades. Resumindo, a análise térmica engloba um grupo de técnicas que permitem estudar as propriedades físicas de uma substância e/ou a sua reactividade em função da temperatura.

As técnicas mais comuns são:

DSC - Differencial Scanning Calorimetry ou Calorimetria Diferencial de Varrimento. Mede a energia calorífica absorvida ou libertada durante o aquecimento ou arrefecimento de uma substância, em relação a uma amostra de referência.

DTA - Differential Thermal Analysis ou Análise Térmica Diferencial. Mede a variação de temperatura decorrente de reacções e/ou transformações físicas durante $o$ aquecimento ou arrefecimento da amostra em estudo, em relação a uma amostra de referência.

TG - Thermogravimetric Analysis ou Termogravemetria. Mede a variação de massa durante o aquecimento ou arrefecimento da amostra.
TMA - Thermomechanical Analysis ou Análise Termomecânica. Mede a variação dimensional durante o aquecimento ou arrefecimento da substância em estudo.

DMA - Dynamic Mechanical Analysis ou Análise Mecânica Dinâmica. Mede a resposta mecânica sob uma tensão periódica (frequência) durante o aquecimento ou arrefecimento.

Apesar de nem sempre ser amplamente divulgada, convém ainda fazer referência a uma outra técnica: a ITC - Isothermal Titration Calorimetry ou Calorimetria Isotérmica de Titulação. Esta técnica mede directamente a energia calorífica libertada ou absorvida numa reacção, a qual é registada em função do tempo ou do reagente titulante.

Dada a grande versatilidade das técnicas anteriormente mencionadas, estas podem ser utilizadas para caracterizar uma vasta gama de materiais para além de polímeros biológicos, nomeadamente outras classes comuns de materiais orgânicos e inorgânicos, como cerâmicas, vidros, metais e ligas, fibras, plásticos, compósitos, etc. Consequentemente as áreas de aplicação estendem-se desde o domínio científico ao industrial, onde adquire particular importância nas Industrias Farmacêutica e da Cosmética, Alimentar, dos Polímeros, seja na fase de investigação e desenvolvimento de um processo ou produto, seja na fase de controlo de qualidade de matérias primas e produtos. Esta grande aplicabilidade advém não só da capacidade destas técnicas em caracterizar quantitativa e qualitativamente uma enorme variedade de materiais, como também pelo facto de o poderem fazer num intervalo alargado de temperaturas.

Estas características acabam por se traduzir por um conjunto de vantagens laboratoriais relativamente a outros métodos analíticos, das quais se pode salientar [1]:

i) A amostra pode ser estudada num intervalo considerável de temperaturas utilizando programas de aquecimento/arrefecimento variados; ii) Praticamente qualquer estado físico da amostra (sólido, líquido, em solução, ou gel) pode ser estudado;

iii) Apenas é necessária uma pequena quantidade de amostra (0.1 $\mu \mathrm{g}-10$ mg);

iv) A atmosfera envolvente da amostra pode ser seleccionada em função da análise pretendida;

v) O tempo requerido para completar um ensaio pode variar de apenas alguns minutos até algumas horas.

Paralelamente a estas vantagens, trata-se ainda de um equipamento de fácil operação que possibilita uma elevada eficiência e produtividade. De facto, uma vez preparado e programado o ensaio, todas as funções, incluindo variações da temperatura e de atmosfera, são executadas automaticamente. Esta "independência" da técnica relativamente ao operador é resultante da configuração do próprio equipamento.

De um modo geral um equipamento de TA inclui um sensor da propriedade física, um forno de atmosfera controlada e um programador, a maioria das vezes constituído por um computador. O programador constitui o módulo de registo e processamento de dados para além de controlar a evolução dos ensaios (intervalos de temperatura, velocidade de aquecimento/arrefecimento, fluxo de gás de purga, etc.).

Actualmente é comum encontrar apenas um programador a funcionar com diferentes módulos de análise térmica. $\mathrm{Na}$ Figura 1 representa-se de modo esquemático uma possível combinação desta instrumentação.

\section{Análise Calorimétrica}

\section{Calorimetria diferencial de varrimento (DSC)}

A calorimetria diferencial de varrimento é uma técnica de análise térmica que regista o fluxo de energia calorífica associado a transições nos materiais em função da temperatura. É um método de variação entálpica, no qual a diferença no fornecimento de energia calorífica entre uma substância e um material 


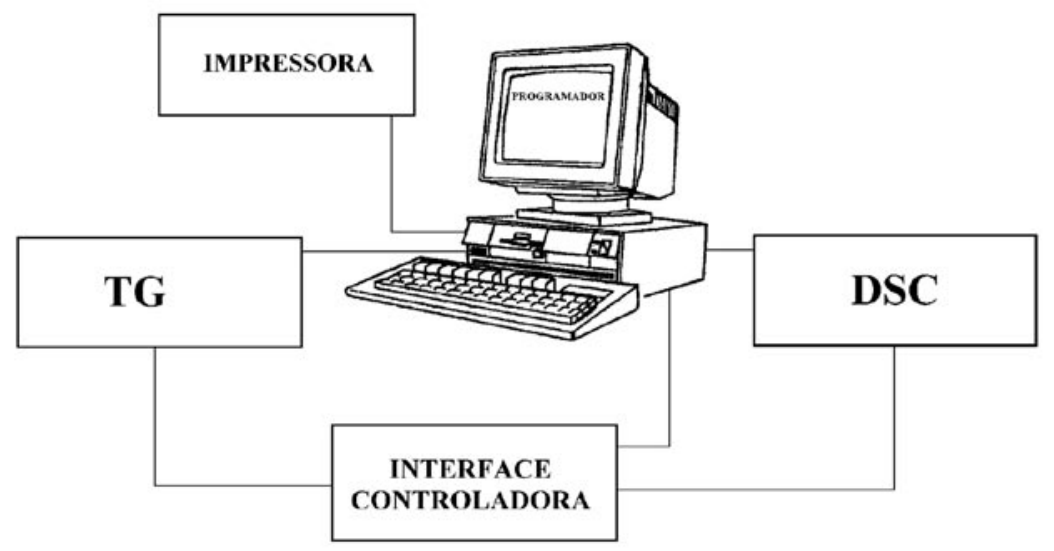

Figura 1 Representação esquemática de instrumentação TG-DSC. de referência é medida em função da temperatura, enquanto a substância em estudo e a referência são submetidas a um mesmo programa de aquecimento, ou arrefecimento, rigorosamente controlado.

Estas medidas fornecem dados qualitativos e quantitativos em processos endotérmicos (absorção de energia calorífica) e exotérmicos (libertação de energia calorífica), permitindo obter informações referentes a alterações de propriedades físicas e/ou químicas como, por exemplo [2, 3]:

- Temperaturas características (temperatura de fusão, cristalização, transição vítrea).
- Grau de cristalinidade de um polímero.

- Diagramas de fase.

- Entalpias de transição de fase e de reacção.

- Estabilidade térmica e oxidativa.

- Grau de pureza.

- Cinética de reacções.

Por este motivo, tal como a maioria das restantes técnicas de análise térmica, a técnica de DSC é amplamente aplicada na caracterização de materiais orgânicos e inorgânicos, cristalinos e amorfos, assim como nas indústrias já anteriormente referidas.

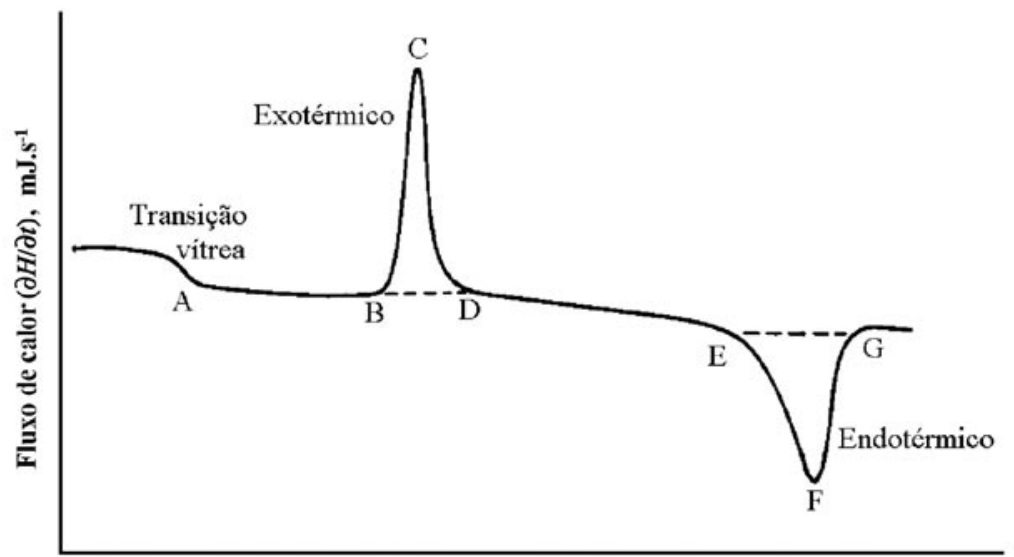

Temperatura $(T), \mathrm{K}$
Figura 2 Curva genérica de DSC para um composto polimérico. $\partial \mathrm{H} / \partial \mathrm{t}$ corresponde ao fluxo de energia calorífica (adaptado de [3]).
Como limitações desta técnica refira-se a dificuldade de interpretação (acontece alguma reacção, mas qual?), requerendo normalmente outros métodos complementares para a interpretação dos resultados. Para além disso necessita de calibração em toda a gama de temperatura. Daí o seu acoplamento com outras técnicas analíticas, como a espectrometria de massa, a espectrometria de infravermelhos de transformadas de Fourier, e a cromatografia de fase gasosa, entre outras, para além das combinações com outras técnicas de análise térmica, como a termogravimetria.

A Figura 2 representa uma curva típica de DSC de uma amostra polimérica.

Em ordenadas representa-se $\left(\frac{\partial H}{\partial t}\right)_{P}$ que corresponde ao fluxo de energia calorífica (variação da entalpia por unidade de tempo) a pressão constante. Dado que a grande maioria dos processos estudados em fases condensadas se processa a pressão constante, e para facilidade de escrita, deixaremos no texto de introduzir o índice; $\partial T / \partial t$ é a taxa de variação da temperatura durante $\mathrm{o}$ varrimento e $(\partial \mathrm{H} / \partial \mathrm{t}) /(\partial \mathrm{T} / \partial \mathrm{t})$, ou seja $\partial \mathrm{H} / \partial \mathrm{T}$, corresponde à capacidade calorífica a pressão constante da amostra, $C_{P}$.

A interpretação dos dados contidos nesta curva leva à identificação de diferentes regiões da mesma. Assim, o pico BCD representa um pico exotérmico, situação em que a temperatura da amostra aumenta relativamente à temperatura do material de referência. Está associado a um decréscimo da entalpia de uma fase ou de um sistema químico. Cristalização, reacções de oxidação ou algumas reacções de decomposição estão associadas a uma libertação de energia calorífica e produzem este género de picos.

O segmento EFG, ilustra um pico endotérmico que pode corresponder a transições de fase, reacções de redução ou algumas reacções de decomposição, correspondendo a uma absorção de energia calorífica. Neste caso em particular representa a temperatura de fusão do material polimérico.

O ponto A, que é acompanhado por um pequeno deslocamento relativamente à 


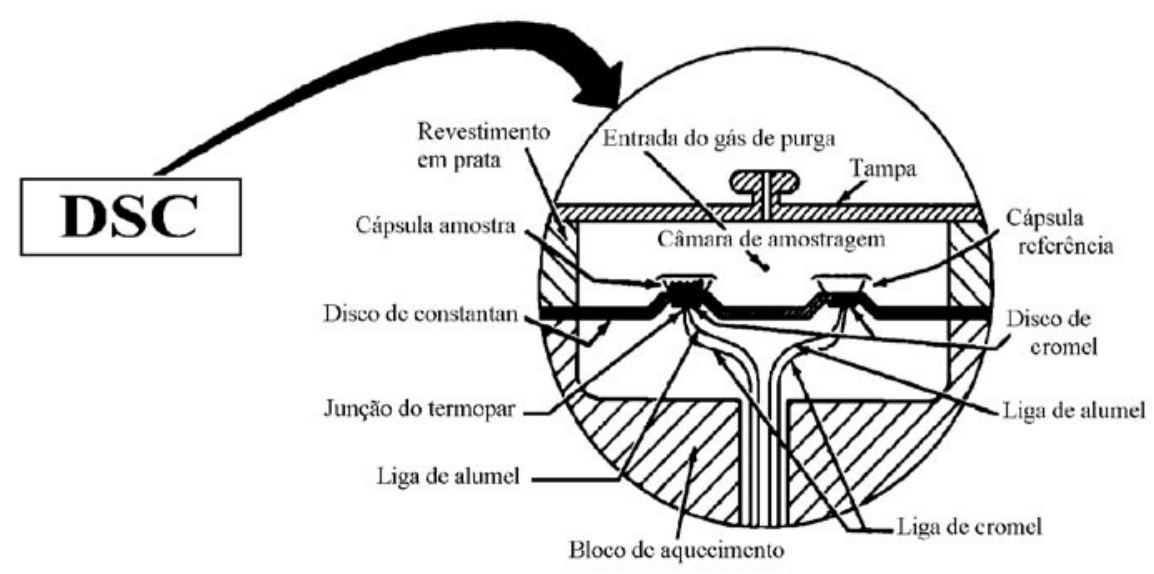

Figura 3 Representação esquemática da secção transversal de um equipamento de DSC da DuPont (adaptado de [3]).

linha de base, corresponde à temperatura de transição vítrea de um polímero. Surge sempre acompanhada de uma variação da capacidade calorífica da amostra.

A variação total de entalpia atribuída a determinado pico, é calculada com base na sua área (formada por exemplo, pelos segmentos $\mathrm{BC}, \mathrm{CD}$ e $\mathrm{DB}$, no caso do pico exotérmico da Figura 2).

\section{Princípios operacionais}

Todos os calorímetros DSC têm em comum várias características. A mais importante, e motivo pelo qual são designados por calorímetros diferenciais de varrimento, é que as medições térmicas são feitas de modo diferencial e contínuo entre duas células.

De acordo com os princípios operacionais, os calorímetros diferenciais de varrimento podem ser divididos em dois tipos: de compensação de potência e de fluxo de energia calorífica [4].

Nos DSC do tipo fluxo de energia calorífica a diferença de temperatura entre a amostra e a referência é medida em função da temperatura ou do tempo, sob condições de temperatura controlada, sendo a diferença de temperatura proporcional à variação do fluxo de energia calorífica $(\partial \mathrm{H} / \partial \mathrm{t})$. A estrutura de um sistema deste tipo encontra-se representada na Figura 3, para um calorímetro da DuPont.

Existe um conjunto de termopares que se encontram ligados sob cada uma das plataformas onde se colocam a amostra e a referência sendo, no caso particular do equipamento da DuPont, constituídos por ligas de cromel e alumel. Um segundo conjunto de termopares mede a temperatura do bloco de aquecimento, no referido caso formados pela junção do disco de constantan de condutibilidade térmica elevada e de um disco de cromel que cobre a parte inferior de cada uma das plataformas. $\mathrm{O}$ facto de a temperatura do bloco de aquecimento ser controlada por um sistema de termopares independentes localizados no próprio bloco, permite programar a velocidade de aquecimento de forma variada, tornando também possível a realização de ensaios isotérmicos.

Quando o bloco de aquecimento é aquecido, ou arrefecido, a uma velocidade programada, as temperaturas da amostra e da referência aumentam, ou diminuem, uniformemente. Durante uma transformação (transição de fase, reacção, fusão, etc.) a amostra liberta ou absorve energia calorífica o que provoca alterações do fluxo de energia calorífica através do disco e, consequentemente, variações na diferença de temperatura entre a amostra e a referência permitin- do a estimativa da entalpia associada a essa transformação [1-3].

Nos calorímetros diferenciais de varrimento do tipo compensação de potência, o princípio operacional é diferente do anteriormente apresentado. As células ou plataformas onde se colocam a amostra e a referência encontram-se equipadas individualmente com um sensor de resistência, que mede a temperatura de cada uma, e uma resistência de aquecimento. Quando é detectada uma diferença de temperatura entre a amostra e a referência devido a uma alteração da amostra, é adicionada energia térmica $(\partial \mathrm{H} / \partial \mathrm{t})$ a uma das células de modo a manter um diferencial de temperaturas nulo entre ambas $\left(T_{\text {amostra }}=T_{\text {ref }}\right)$. Uma vez que essa quantidade de energia é exactamente equivalente à quantidade de energia absorvida ou libertada na transformação ocorrida na amostra, o seu registo fornece uma medida calorimétrica directa da energia associada à transformação [1,4].

Como todos os instrumentos de medida, os aparelhos de DSC apresentam um certo tempo de resposta devido a alguma resistência térmica, o que se traduz pelo aparecimento de desvios da linha de base. Para aumentar o rigor das determinações o sinal calorimétrico (SC) determinado pelo aparelho, e que corresponde a $\partial \mathrm{H} / \partial \mathrm{t}$, é calibrado [4,5] determinando-se uma constante de ca- 
libração $K$, tal que $K=\frac{S C}{\dot{Q}_{\text {real }}}$, sendo $\dot{Q}_{\text {real }}$ o fluxo de energia calorífica realmente dissipado na célula ${ }^{1}$. A constante $K$ é assim função da temperatura, da atmosfera em torno das células e de quaisquer resistências que conduzam a perdas de energia calorífica.

A calibração para a entalpia pode ser feita por efeito Joule através de uma sonda de propriedades térmicas conhecidas, como é o caso de calorímetros DSC da SETARAM, ou, tanto para a entalpia como para a temperatura, com materiais de referência ${ }^{2}$ (metais, cerâmicas ou líquidos) com propriedades bem definidas na região de temperaturas que se pretende trabalhar e utilizando diferentes velocidades de aquecimento/ arrefecimento, visto que a temperatura a que ocorre uma dada transformação está dependente da velocidade de varrimento.

As temperaturas de fusão de padrões como o índio, estanho, chumbo, etc., são utilizadas para calibrar a temperatura indicada pelo equipamento, enquanto que a entalpia de fusão destes metais é utilizada na calibração do sinal calorimétrico.

Em termos experimentais estas características traduzem-se por alguns benefícios práticos. Por exemplo, além de possibilitarem medidas de baixos valores de variação de entalpia, possibilitam ainda a utilização de pequenas quantidades de amostra (geralmente entre 5 e 20mg). Esta última particularidade revela-se de grande utilidade visto que muitas vezes os ensaios são destrutivos. O tempo de cada ensaio depende da velocidade de aquecimento/arrefecimento utilizada (geralmente 5 a $20^{\circ} \mathrm{C} / \mathrm{min}$ ) e da gama de temperaturas a ensaiar, podendo durar de alguns minutos a algumas horas.

\section{Calorimetria isotérmica de titulação (ITC)}

A calorimetria isotérmica de titulação é uma técnica analítica que, tal como as técnicas de TA anteriormente referidas, é amplamente usada em áreas de investigação muito diferentes (química e bioquímica, física e biofísica, biotecnologia, biomedicina, farmacologia), assim como nas indústrias de cosméticos, alimentação, processos de controlo, etc.

Basicamente, a técnica de calorimetria isotérmica de titulação permite a medição directa da energia calorífica libertada ou absorvida ao longo de uma reacção, em que o que está em jogo são interacções inter- e intra-moleculares. Face a esta explicação, facilmente se compreende a sua aplicação a polímeros biológicos, pois associações como proteína-ligando, proteína-proteína e proteína-ADN/ARN são exemplos entre outros, de indubitável interesse. Nestes casos, se o efeito térmico da interacção for suficientemente grande, a estequiometria, a entalpia de formação e a constante de equilíbrio de formação destes complexos, geralmente denominada de constante de união do complexo, pode ser determinada sem ambiguidade. Deste modo, a energia de Gibbs de formação do complexo pode ser calculada:

$$
\Delta G^{0}=-R T \ln K_{e q}
$$

e consequentemente também a entropia do processo [6]:

$$
\Delta S^{0}=\left(\frac{\Delta H^{0}-\Delta G^{0}}{T}\right)
$$

Se este procedimento de titulação calorimétrica for repetido a diferentes temperaturas será possível determinar a variação da capacidade calorífica. Este parâmetro reveste-se de particular importância pois permite, por exemplo, estimar os efeitos da desidratação de grupos polares e apolares que acompanham a formação do complexo.

O êxito desta técnica deve-se principalmente a um conjunto de vários factos relevantes. A maioria das interacções liberta ou absorve energia sob a forma de energia calorífica. Esta energia calorífica é medida directamente a pressão constante, ou seja, pode afirmar-se que a entalpia efectiva da reacção é medida de forma directa. Por outro lado, existe actualmente uma base metodológica e teórica bem estabelecida para analisar dados experimentais, incluindo os de sistemas relativamente complexos, o que proporciona a determinação da estequiometria e dos parâmetros termodinâmicos da reacção em estudo. No entanto, dada a inespecificidade intrínseca na detecção do efeito térmico, e a consequente incapacidade da titulação calorimétrica em detectar a interacção que origina a energia calorífica, é necessário recorrer à ajuda de outras técnicas específicas para interpretar os valores dos parâmetros termodinâmicos em termos moleculares.

\section{Princípios operacionais}

Adoptando como critério de classificação o princípio de funcionamento, os calorímetros isotérmicos de titulação de elevada sensibilidade utilizados em estudos de interacção de biopolímeros, podem ser englobados em duas categorias. Por um lado aqueles que utilizam um bloco de elevada capacidade calorífica, a temperatura constante, e que se baseiam na condução de energia sob a forma de energia calorífica através de sensores que detectam o efeito térmico produzido pela interacção. Por outro, aqueles que se podem chamar de adiabáticos visto que funcionam por compensação do efeito térmico num compartimento adiabático.

O primeiro tipo de calorímetro ITC a que se fez referência corresponde em geral à configuração esquematizada na Figura 4. Pode observar-se uma configuração diferencial com duas células, em que uma actua como vaso de reacção e a outra como referência. Os efeitos térmicos produzidos em cada uma das células são detectados pelos correspondentes sensores ou termopares ligados em oposição. Nos casos de máxima simetria utilizam-se seringas de injecção idênticas contendo um dos reagentes, geralmente o ligando, $L$, que irá interactuar com o biopolímero, B, dissolvido

\footnotetext{
1 Utiliza-se a notação matemática da derivada em ordem ao tempo da grandeza com o ponto superior.

2 De preferência certificados (MRC), onde se certifica, p.ex. a entalpia e temperatura de fusão de metais puros.
} 
num tampão T (o mesmo no qual se dissolve a macromolécula).

A agitação mantém-se durante o processo de injecção, que ocorre simultaneamente em ambas as células. Uma das células, a célula de reacção, contém a solução do biopolímero, enquanto que a outra, célula de referência, contém apenas o tampão.

Não obstante, alguns calorímetros deste tipo não incluem a injecção nem a agitação simultânea de ambas as células. Nestes casos torna-se necessário efectuar um ensaio em branco para determinar os efeitos térmicos associados principalmente à agitação.

O outro tipo de calorimetro mencionado e que se encontra representado na Figura 5 é actualmente um dos equipamentos mais difundidos na comunidade científica especializada em estudos de interacção em cinéticas enzimáticas e em processos que conduzem ao enrolamento de proteínas, e em interacções do tipo proteína-pequenos ligandos, enzima-inibidor, proteína-proteína, hormona-receptor e ADN-proteína.

Como anteriormente referido, trata-se de um calorímetro que funciona por compensação do efeito térmico num compartimento adiabático. Sendo um calorímetro diferencial, faz um uso passivo da célula de referência. Ambas as células calorimétricas têm a forma de cilindros planos (com elevada relação base/altura do cilindro) sobre cujas faces externas se estendem finas termolâminas.

Durante um ensaio uma pequena potência constante e com uma tensão inferior a um milivolt é dissipada na termolâmina da célula de referência, activando-se o sistema de compensação que iguala as temperaturas de ambas as células e produz a linha de base experimental. Um efeito exotérmico ou endotérmico afasta temporariamente a potência de compensação do valor estacionário, produzindo-se um pico característico sobre a linha de base de cuja integração se extrai a energia calorífica implicado no processo. As células encontram-se suspensas somente através de largos tubos de acesso no interior de um cilindro.

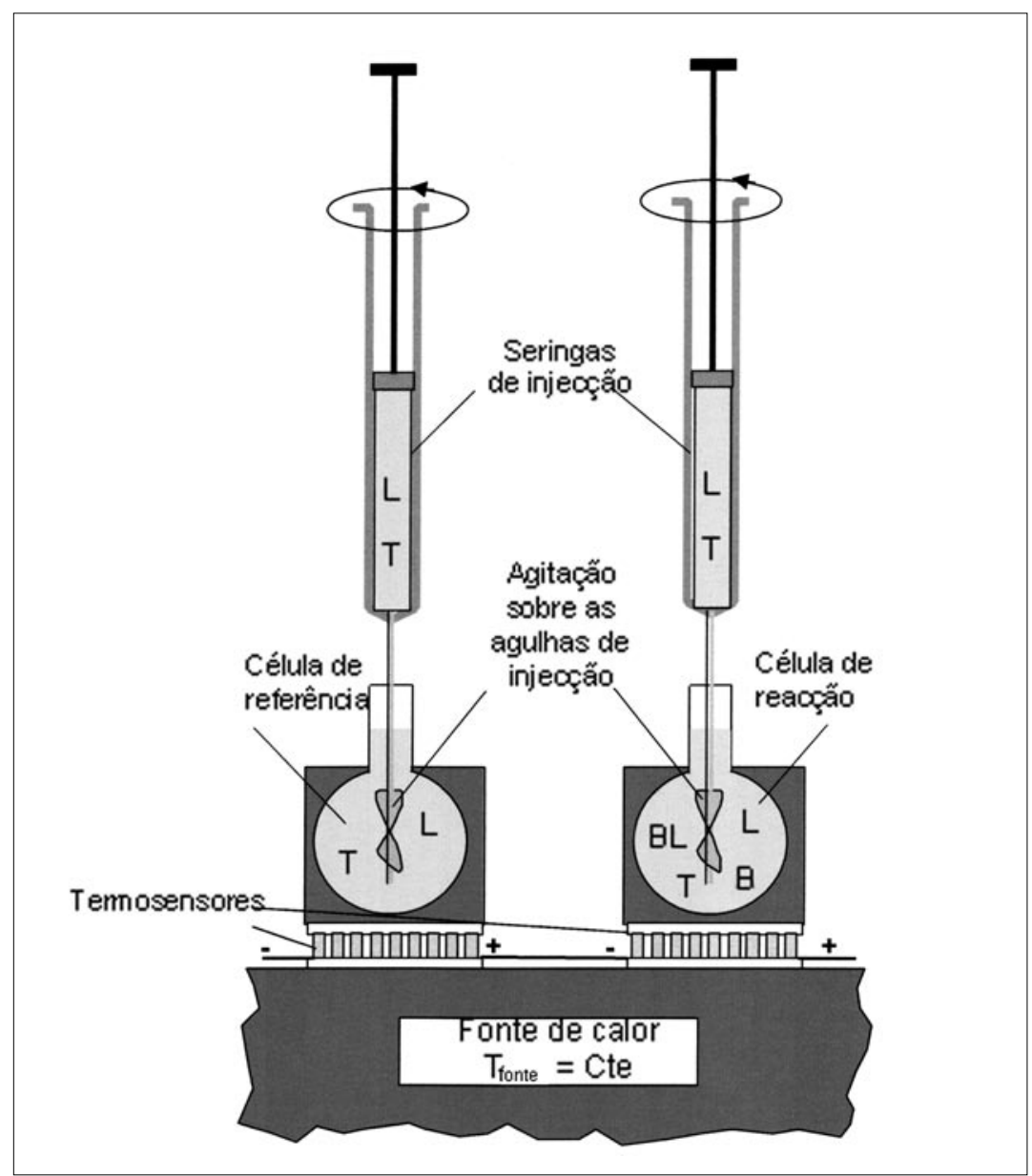

Figura 4 Esquema geral de um calorímetro isotérmico de titulação baseado no princípio da condução de energia sob a forma de energia calorífica através de sensores de baixa impedância térmica. L, T e B representam respectivamente moléculas de ligando, de tampão e de biopolímero (adaptado de [6])

Com o objectivo de proporcionar um compartimento adiabático para as células, a temperatura deste cilindro é controlada de forma a mantê-la tão próxima da temperatura das células quanto possível. Para isso uma termopilha mede continuamente a diferença de temperatura entre células e cilindro e um sistema de controlo em circuito fechado actua sobre uma termolâmina distribuida uniformemente sobre a superfície do cilindro. Relativamente ao controlo da temperatura, consegue-se através da circulação de água a partir de um banho termostático exterior. Para acentuar o controlo adiabático e eliminar a condensação de vapor de água, tanto mais importante quanto menor a temperatura de trabalho, faz-se vácuo no interior do cilindro.

O sistema de injecção-agitação é uma das partes mais críticas do equipamento. Do seu correcto funcionamento depen- de a fiabilidade dos volumes de injecção (de 2 a $5 \mu \mathrm{L}$ num ensaio padrão), da eficácia da homogenização da mistura reaccional e de um baixo nível de ruído compatível com a elevada sensibilidade requerida para detectar os efeito térmicos, geralmente de apenas algumas dezenas de microjoules. As seringas de injecção são seringas de precisão em vidro providas com longas agulhas de aço inoxidável que têm no seu extremo uma pequena palheta para agitação.

Em ambos os tipos de calorímetros isotérmicos de titulação, o sinal associado ao efeito térmico transitório de uma reacção/interacção entre os dois reagentes, sejam por exemplo ligando e biopolímero, apresenta um pico com a forma característica da resposta de um sistema de segunda ordem a um pulso de potência de curta duração (Figura 6). A energia calorífica associada obtém-se através da área delimitada pelo pico e a 


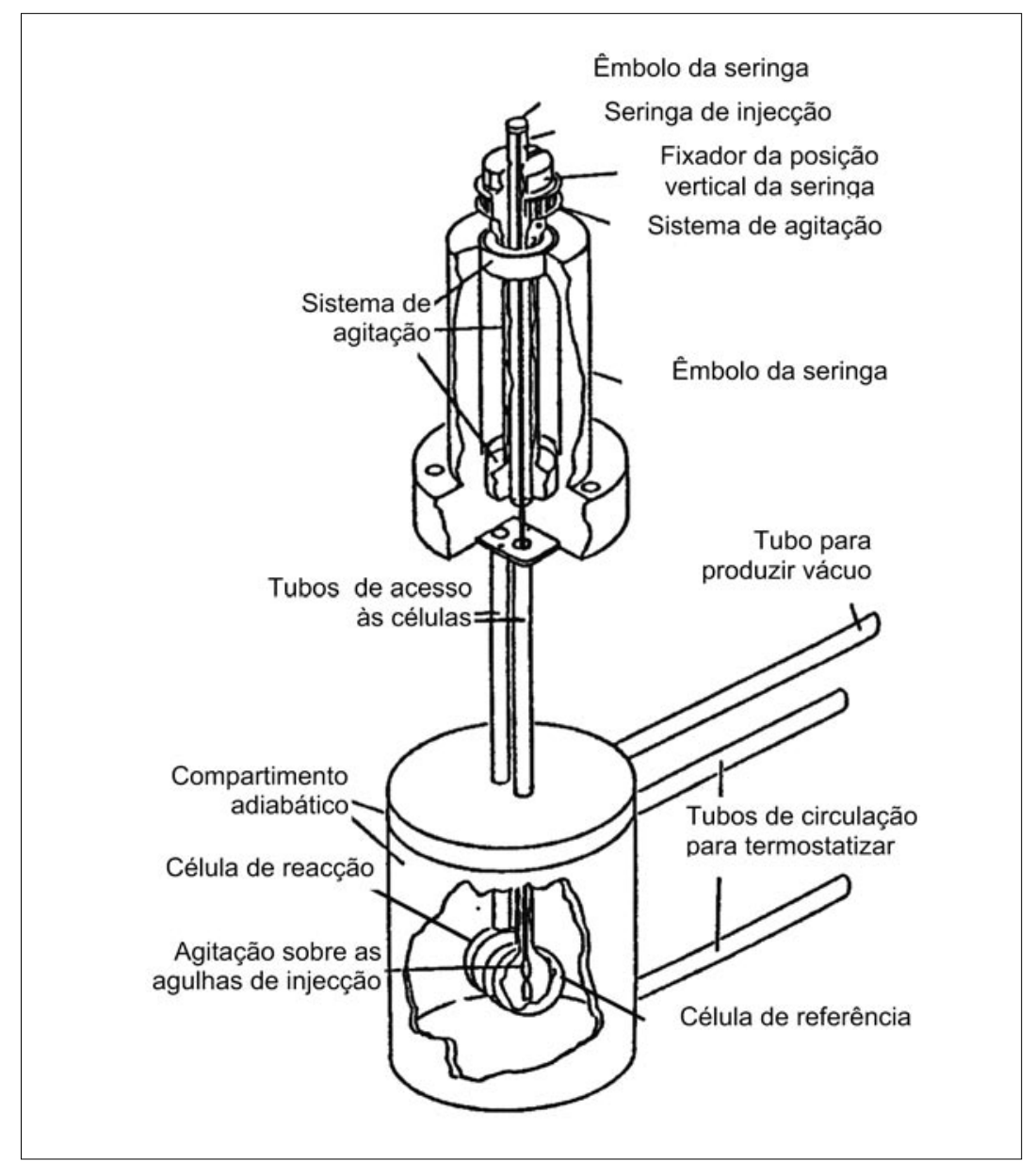

Figura 5 Esquema das células calorimétricas, cilindro adiabático e do conjunto injector/agitador de um calorímetro de titulação baseado no princípio de medida por compensação do efeito térmico num compartimento adiabático (adaptado de [6]).

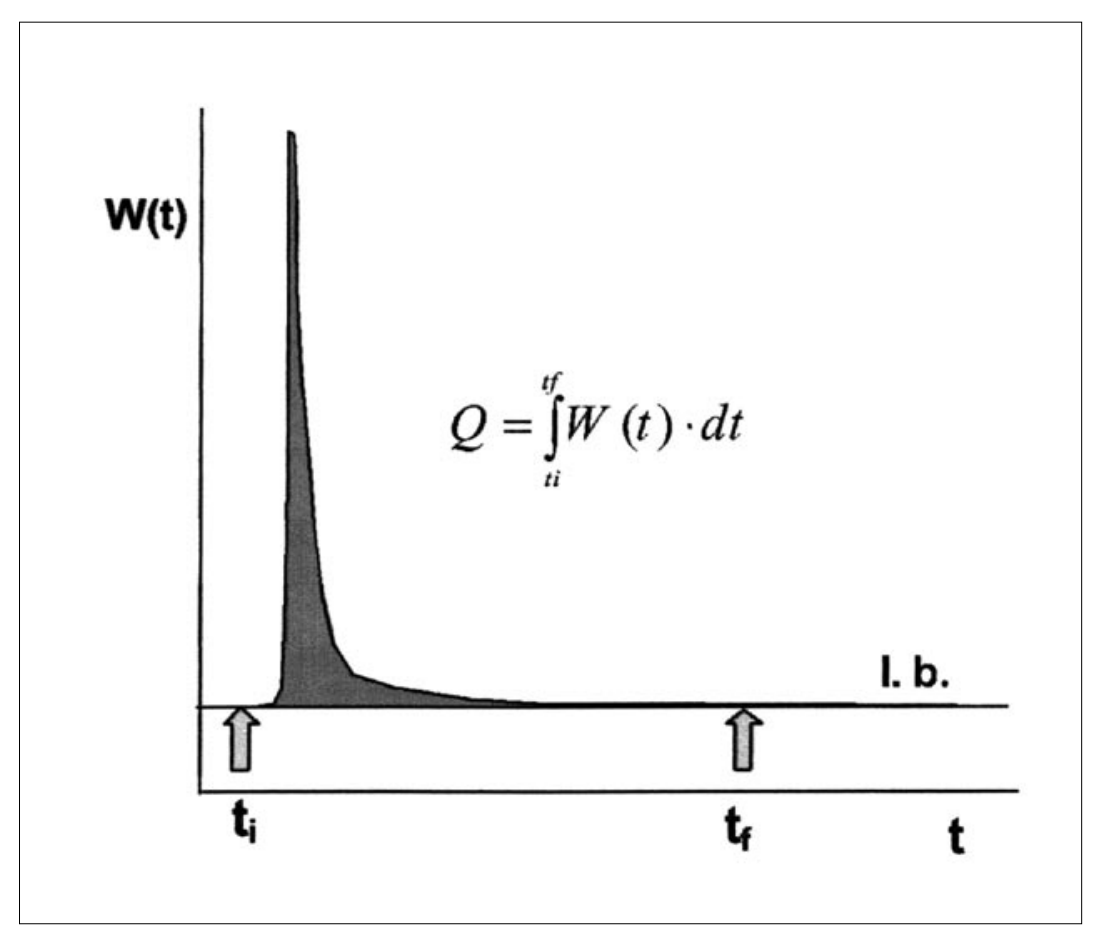

Figura 6 Pico característico de resposta a uma injecção de um reagente (ligando) sobre outro que se encontra na célula reaccional (biopolímero). A energia calorífica gerada na reacção é obtida por integração da função W(t) sobre a linha de base, l.b. (adaptado de [6]). linha de base interpolada entre o sinal estacionário antes e após injecção.

\section{Conclusões}

Actualmente, devido ao facto de poder ser utilizado na concepção de aplicações biomédicas inovadoras e na obtenção de moléculas modificadas para aplicação industrial, o conhecimento da estrutura dos polímeros biológicos reveste-se de particular importância. A versatilidade das técnicas calorimétricas actuais, capazes de detectar infímas variações de energia calorífica associadas a alterações das propriedades físicas e/ou reactividade das macromoléculas biológicas, contribui de forma inequívoca para uma melhor compreensão das macromoléculas e dos processos onde intervêm.

\section{Agradecimentos}

Os autores agradecem ao Prof. Manuel Minas da Piedade pela leitura atenta do manuscrito e pelas sugestões propostas. M. H. Casimiro agradece uma bolsa da Fundação para a Ciência e Tecnologia no âmbito do III Quadro Comunitário de Apoio (bolsa SFRH/BD/2862/2000).

\section{Bibliografia}

1. T. Hatakeyama, F.X. Quinn, Thermal analysis - Fundamentals and applications to polymer science, John Wiley \& Sons, Ltd, New York, 1994.

2. H. Willard, L.Jr. Merrit, J. Dean, Análise Instrumental, Fundação Calouste Gulbenkian, Lisboa, 1979.

3. DuPont Instruments, Differential scanning calorimetry - DSC 910 Operator's manual, Wilmington, 1990.

4. G. Höhne, W. Hemminger, H.-J. Flammershiem., Differential Scanning Calorimetry - An Introduction for Practitioners, Springer Verlag, Berlin, 1996.

5. C. A. Nieto de Castro, M. J. V. Lourenço, M. B. O. Sampaio, "Calibration of a DSC: its importance for the traceability and uncertainty of thermal measurements" Thermochimica Acta, 347 (2000) 85-91

6. O.L. Mayorga, Curso de Doctorado de Microcalorimetria, Departamento de Química Física, Faculdad de Ciencias, Universidad de Granada, 2000. 
A TA INSTRUMENTS é lider mundial em reologia com uma focagem sem paralelo na indústria e investigação.

o compromisso com a inovação é comprovado; o desejo de fazer medidas reológicas melhor do que os seus concorrentes comprova-se pelos contínuos avanços nos seus diferentes produtos. A aquisição da firma Rheometrics permite a oferta de todos os tipos de sistemas existentes no mercado, desde sistemas operando a tensão controlada como sistemas operando a deslocamento controlado. O modelo AR 2000 é o equipamento mais vendido no mercado. Esta unidade possui capacidades de medição sem comparação e um conjunto de acessórios único. Entre outras, podem citar-se:

- Motor de arrastamento, modelado permitindo uma vasta gama linear de torções

- Inércia de baixo valor para o melhor controle de tensão e deslocamento

- Controle directo da tensão e oscilação em toda a gama de trabalho do equipamento

- Desenho ultra robusto do corpo do equipamento

- Transdutor de força manual separado

- Electrónica isolada do resto do equipamento

- Sistemas periféricos de troca rápida e identificação automática (Smart Swap)

- Representação em tempo real da forma de onda em oscilação

- O único sistema de tensão controlada disponível num corpo único de alumínio

\section{UM Nível SUPERIor EM CALORIMETRIA}

A TA Instruments fabrica diversos tipos de equipamentos na área da calorimetria. Para além dos calorímetros de varrimento, fornece também equipamento de análise termogravimétrica, equipamentos combinados de DSC/TG, DMA e TMA. O DMA Q800 é o estado da arte em análise dinâmico/mecânica.

A unidade utiliza uma tecnologia semelhante à dos reómetros, de atrito reduzido.

$O$ deslocamento é medido utilizando um descodificador óptico que proporciona elevada sensibilidade e resolução. A unidade é utilizada na caracterização de propriedades viscoelásticas de vários tipos de materiais sólidos e é ideal para aplicações em materiais de forte resistência incluindo compósitos.

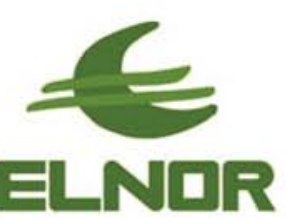

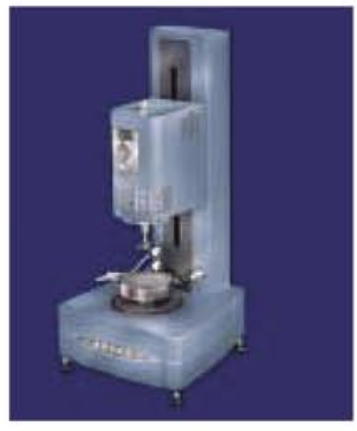

\section{TECNOLOGIA T T PARA CALORIMETRIA DIFERENCIAL DE VARRIMENTO (DSC)}

Um desenho superior para desempenhos de alto nível. $\mathrm{O}$ novo sensor $\mathrm{T}_{0}$ melhora a resolução em $300 \%$ comparativamente aos sistemas

tradicionais.

A estabilidade da

linha de base e a sensibilidade

melhoram de uma ordem de magnitude em relação também aqueles sistemas. A possibilidade de automação dá ao utilizador resultados rápidos, reprodutíveis e exactos.

A utilização do chamado DSC modulado, torna a análise dos dados. ainda mais simples, trazendo mais luz à análise de alguns eventos de difícil interpretação.

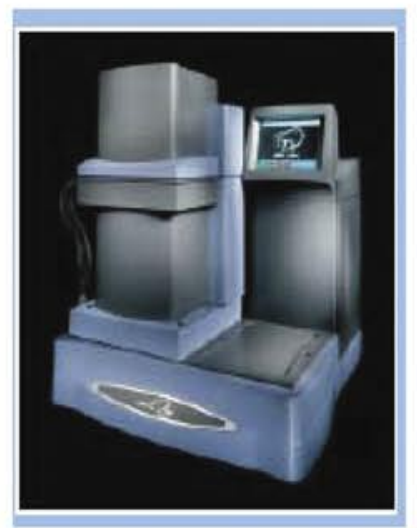

ELNOR - Equipamentos Técnicos e de Laboratório, S.A.

B R.D.Frei Jerónimo de Brito e Melo № 835 • 4465-642 LEÇA DO BALIO • PORTUGAL

$\triangle$ P.O.Box $1019 \bullet 4470$ MAIA CODEX • PORTUGAL

- Phone: (351 22) 9050400

- Fax : (351 22) 9050499 